\title{
Current radiation risks from occupational exposure in Russian nuclear industry
}

\author{
Viktor Ivanov ${ }^{*}$, Alexander Korelo, Sergey Chekin, and Konstantin Tumanov \\ A. Tsyb Medical Radiological Research Center, Obninsk, Russia
}

For monitoring risks of occupational radiation exposure to workers of Russian nuclear industry the system ARMIR is used. The system was developed at the State Corporation ROSATOM in cooperation with the Russian Scientific Commission on Radiological Protection and the National Radiation Epidemiological Registry [1-3].

The ARMIR system is designed on the basis of principles and methods for calculation of radiation risk recommended by ICRP [4]. During the creation of the system algorithms of calculation of different radiation risk measures from multiple radiation exposure, specialized software and database were developed. Justification of adaptability of mathematical models based on follow-up data on A-bomb survivors in Japan to Russian conditions was carried out.

The system ARMIR was first used in the "Mayak Production Accociation" in 2006. At present the system is used in more than 100 radiation and nuclear hazardous sites of the ROSATOM.

ARMIR databases consist all information necessary for calculating radiation risks, that is employee's ID number, gender, date of birth, as well as annual radiation doses received by a regulatory monitored worker being registered on a database maintaining records of the doses received by each individual dosimeter wearer. More than 60 thousand personal records are collected annually (Table 1).

Table 1. Basic characteristic of occupational radiation exposure in main divisions of the Rosatom.

\begin{tabular}{|c|c|c|c|c|c|}
\hline Division & $\begin{array}{c}\text { Number of } \\
\text { workers }\end{array}$ & $\begin{array}{c}\text { Average } \\
\text { age, years }\end{array}$ & $\begin{array}{c}\text { Average } \\
\text { annual } \\
\text { dose, mSv }\end{array}$ & $\begin{array}{c}\text { Average } \\
\text { cumulative } \\
\text { dose, mSv }\end{array}$ & $\begin{array}{c}\text { Average } \\
\text { length of } \\
\text { work, } \\
\text { years }\end{array}$ \\
\hline Electric power division & 27427 & 42.0 & 1.77 & 51.2 & 12.4 \\
\hline Fuel division & 7637 & 43.7 & 1.20 & 19.7 & 11.1 \\
\hline Nuclear weapons complex & 5131 & 38.5 & 3.39 & 30.8 & 5.8 \\
\hline Mining division & 13959 & 42.9 & 1.82 & 31.4 & 11.9 \\
\hline Nuclear and radiation safety complex & 3334 & 45.1 & 1.05 & 31.0 & 14.1 \\
\hline Innovation management unit & 4578 & 48.3 & 2.17 & 41.2 & 14.9 \\
\hline ROSATOM & 62349 & 42.8 & 1.83 & 39.3 & 11.9 \\
\hline
\end{tabular}

* Corresponding author: nrer@obninsk.com 
During the recent years average risk value does not exceed 0.00008 (Table 2).

Table 2. Results of monitoring radiation risks in main ROSATOM divisions.

\begin{tabular}{|c|c|c|}
\hline Division & $\begin{array}{c}\text { Average } \\
\text { individual risk }\end{array}$ & $\begin{array}{c}\text { Average Safety } \\
\text { Index of Potential } \\
\text { Exposure, \% }\end{array}$ \\
\hline Electric power division & $1.2 \mathrm{E}-04$ & 67.2 \\
\hline Fuel division & $3.1 \mathrm{E}-05$ & 76.5 \\
\hline Nuclear weapons complex & $5.0 \mathrm{E}-05$ & 65.0 \\
\hline Mining division & $2.0 \mathrm{E}-05$ & 48.0 \\
\hline Nuclear and radiation safety complex & $6.8 \mathrm{E}-05$ & 76.9 \\
\hline Innovation managment unit & $1.0 \mathrm{E}-04$ & 67.2 \\
\hline ROSATOM & $7.9 \mathrm{E}-05$ & 67.0 \\
\hline
\end{tabular}

Data accumulated in the ARMIR are used for calculation of the Safety Index of Potential Exposure, SIPE. The index takes into account limitation of annual generic risk value, $<2 \cdot 10^{-4}$. This allows monitoring radiation protection at ROSATOM facilities with regard to sources of potential exposure. The level of radiation protection at a nuclear facility in relation to sources of potential radiation exposure is considered as optimized if the SIPE is above $50 \%$ and does not reduce with time. Average safety index of potential radiation exposure in ROSATOM achieves $67 \%$.

Information on existing radiation risks in nuclear industry is brought to the notice of professional association and interested public via ROSATOM Annual Public Report and industry-specific mass media.

Estimation of existing radiation risks and their prediction are used for making managerial decisions in relation to radiation exposure and radiation protection of workers. The estimates should be taken into account when planning accident rescue operations and setting up emergency teams.

\section{References}

1. V.K. Ivanov, A.F. Tsyb, A.P. Panfilov, A.M. Agapov, O.V. Kaidalov, A.M. Korelo, M.A. Maksioutov, S.Y. Chekin, P.V. Kashcheyeva, Estimation of individualized radiation risk from chronic occupational exposure in Russia, Health Phys. 97, 2 107114 (2009).

2. S.G. Mikheenko, et al., ARMIR: the system for estimation of radiological risk from occupational exposure. Proceedings of the International Conference on Occupational Radiation Protection (Vienna, IAEA, 2014).

3. V.K. Ivanov, A.M. Korelo, K.A. Tumanov, S.Yu. Chekin, S.A. Adamchik, S.G. Mikheenko, A.P. Panfilov, V.Yu. Usoltsev, Monitoring of occupational radiation risks of nuclear industry workers (ARMIR system), Radiation and Risk 25, 1 16-24 (2016).

4. International Commission on Radiological Protection, The 2007 Recommendations of the International Commission on Radiological Protection, Publication 103, Ann. ICRP 37, 2-4 (2007). 